\title{
A case of acute skin failure misdiagnosed as a pressure ulcer, leading to a legal dispute
}

\author{
Jung Hwan Kim, Hea Kyeong Shin, Gyu Yong Jung, Dong Lark Lee \\ Department of Plastic and Reconstructive Surgery, Dongguk University College of Medicine, Gyeongju, Korea
}

It is difficult to differentiate acute skin failure (ASF) from pressure ulcer (PU). ASF is defined as unavoidable injury resulting from hypoperfusion caused by severe dysfunction of another organ system. We describe a case of ASF mistaken as PU that resulted in a legal dispute. A 74-year-old male patient was admitted to our intensive care unit with sepsis due to bacterial pneumonia. Despite the use of air cushions and regular position changes, skin ulcerations occurred over his occiput, back, buttock, elbow, and ankle. After improvement in his general condition, he was transferred to the department of plastic and reconstructive surgery. Debridement was performed immediately, followed by conservative treatment (including a vacuum-assisted closure device) for 6 weeks. The buttock and occiput wounds were treated surgically. Despite complete healing, his caregivers sued the hospital for failing to prevent PU formation. ASF is a pressure-related injury resulting from hemodynamic instability due to organ system failure. Unlike PU, ASF may occur despite the implementation of all appropriate preventive measures. Furthermore, misdiagnosis of ASF as PU can lead to litigation. Therefore, it is critical for the proper diagnosis to be made quickly, and for physicians to explain that ASF occurs despite proper preventative treatment.

Keywords Pressure ulcer / Skin / Intensive care units / Necrosis
Correspondence: Hea Kyeong Shin Department of Plastic and Reconstructive Surgery, Dongguk University College of Medicine, 87 Dongdae-ro, Gyeongju 38067, Korea

Tel: +82-54-770-1461

Fax: +82-54-770-1469

E-mail: shinheakyeong@hanmail.net

Received: 22 Jan 2018 - Revised: 8 May $2018 \bullet$ Accepted: 13 Jun 2018

pISSN: 2234-6163 • elSSN: 2234-6171 • https://doi.org/10.5999/aps.2018.00087• Arch Plast Surg 2019;46:75-78

\section{INTRODUCTION}

Patients in a poor medical state often develop pressure ulcer (PU) during hospitalization, and if preventive measures are inappropriate, this can be interpreted as reflecting carelessness of the medical team. However, acute skin failure (ASF) can develop despite the adoption of normal precautionary measures [1]. ASF is caused by skin hypoperfusion due to hemodynamic instability [2]. However, ASF is unfamiliar and has no definite diagnostic criteria; thus, ASF can be misdiagnosed as PU. In the worst cases, it can result in legal consequences.

We report a case of ASF which was misdiagnosed as PU in or- der to shed light on this ill-defined disease entity, so that physicians can better cope with patients who actually have ASF. The patient and the caregivers were informed about this study, and their consent was obtained before submission.

\section{CASE}

A 74-year-old male patient visited Dongguk University Gyeongju Hopital with high fever and a drowsy mental state. He was admitted to the intensive care unit (ICU) because of septic shock due to bacterial pneumonia. His mean arterial pressure dropped to $50-60 \mathrm{mmHg}$. Initial blood examination revealed the follow- 
ing: leukocytes, 38,740/ $\mu \mathrm{L}$; myoglobin, 7,896 ng/mL; creatine kinase $>3,000 / \mu \mathrm{L}$. The amount of urine was less than $300 \mathrm{~mL} /$ day. Hemodynamic instability occurred, and was attributed to acute respiratory failure and acute renal failure. After 2 weeks of treatment in the ICU, he began to regain health gradually, and his vital signs stabilized.

In the ICU, to prevent PU, position changes were performed every 2 hours, using an air mattress. Pressure on bony prominences was dispersed by using a donut-shaped pouch. Three days later, despite efforts to prevent PU, multiple skin ulcers had developed that were not present at admission. The lesions developed simultaneously and progressed rapidly. Of particular note, the lesion on the left buttock was not round, but was pearshaped, unlike common PU. On the 14th hospital day, his occiput, back, elbow, left buttock, and ankle wounds showed necrosis (Fig. 1). Then, he was transferred to the department of plastic and reconstructive surgery to treat multiple skin ulcerations.

Escharectomy and debridement of necrotic tissue were performed (Fig. 2). The ulcers of the back and left elbow were covered with a local advancement flap. After confirming that the infection had been controlled, we applied vacuum-assisted closure (VAC) to the left buttock. Six weeks after applying VAC, granulation had proceeded properly (Fig. 3). Therefore, we decided to close the left buttock and occipital wounds surgically. The left buttock was closed using a superior gluteal artery perforator-

\section{Fig. 1. Developement of multiple skin ulcerations}

Despite the use of air cushions and regular position changes (every 2 hours), skin ulcerations developed in several locations. (A) Left buttock, (B) left back, (C) occiput, and (D) left ankle.
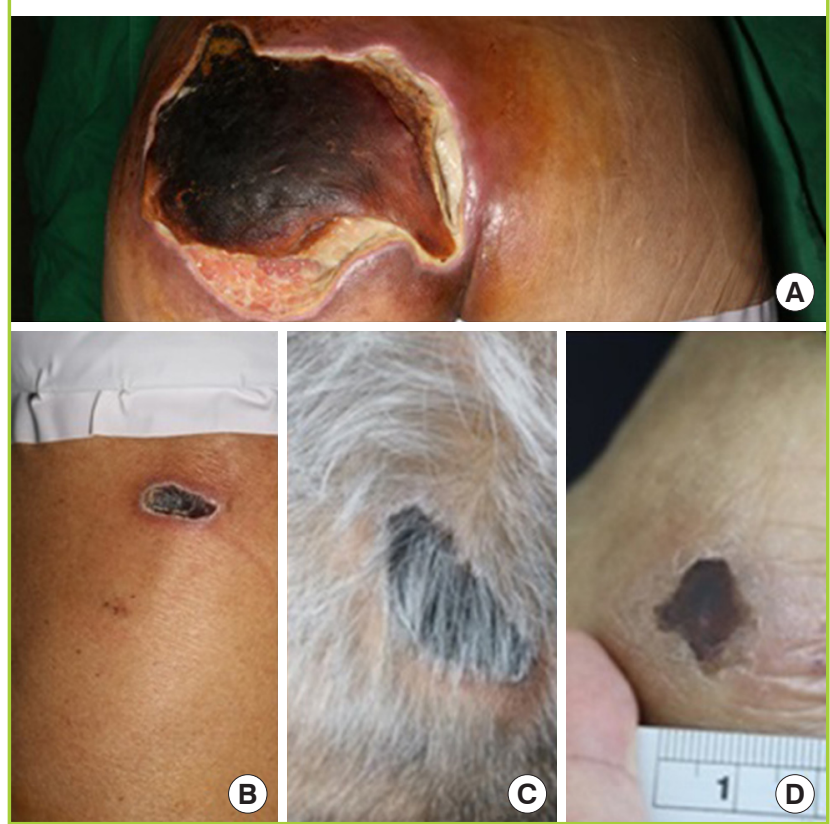

based advancement-rotation flap with a split-thickness skin graft, and the occipital wound was closed using a bilateral advancement flap. On postoperative day 21, partial necrosis developed on the skin graft area and responded to conservative treatment (Fig. 4). Subsequently, the patient's caregivers sued the hospital for failing to prevent PU. The litigation was resolved satisfactorily, but the medical team members wasted considerable time and suffered from the caregivers' complaints.

\section{DISCUSSION}

ASF refers to a state of tissue hypoperfusion that leads to tissue death, and may occur simultaneously with other conditions in the critically ill [1]. Although the skin accounts for $10 \%$ to $15 \%$ of the total body weight, it requires $25 \%$ to $33 \%$ of cardiac output, and thus, is the largest single organ of the human body [3].

\section{Fig. 2. Escharectomy performed on the left buttock \\ Escharectomy and debridement of the necrotic tissue were prompt- ly performed.}

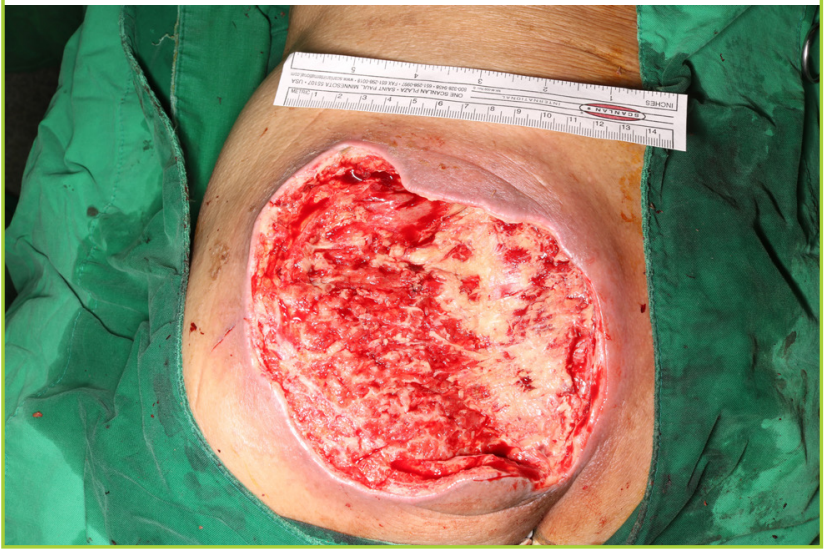

\section{Fig. 3. The buttock cleaned with VAC}

Six weeks after applying vacuum-assisted closure (VAC), the lesion on the left buttock was clean and the progression of granulation was confirmed.

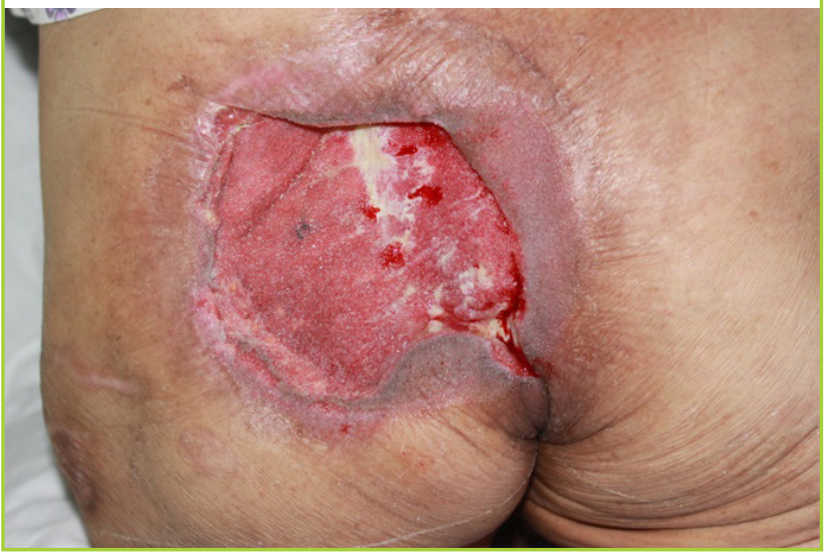




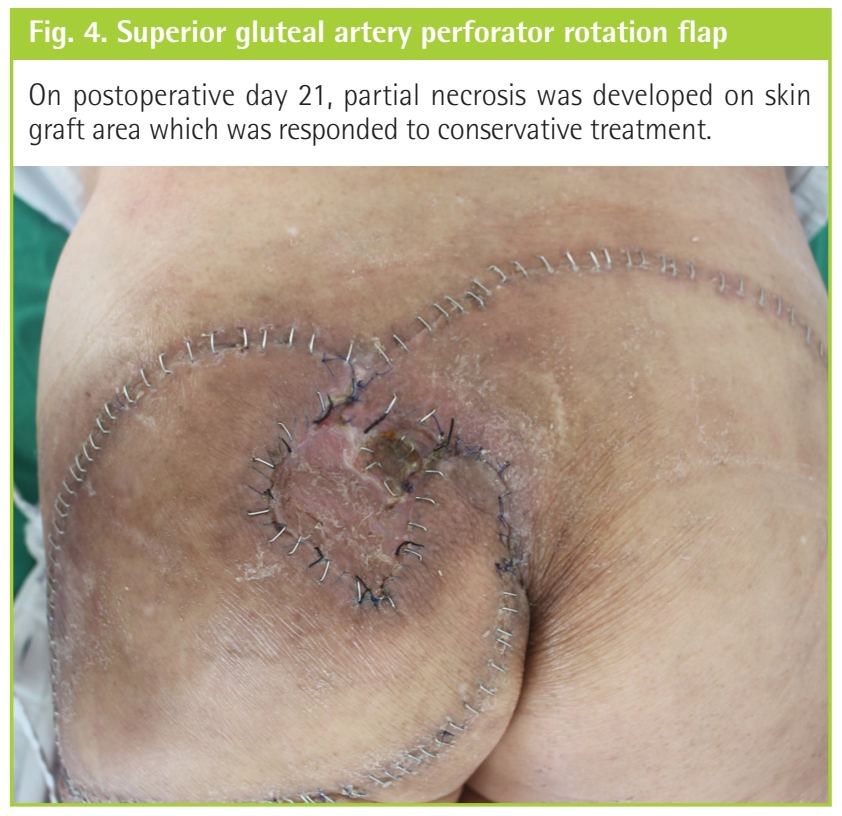

Schank [4] defined ASF as a pressure-related injury concurrent with acute illness, as manifested by hemodynamic instability due to major organ system compromise, whereas PU is defined as an ulcer caused by continuous or repetitive pressure applied to a bony prominence resulting in tissue ischemia with necrosis $[2,3]$.

Many authors contribute to confusion by interchangeably using terms that refer to unavoidable PU-like lesions, such as ASF, unavoidable PU, and Kennedy terminal ulcer. Skin failure is defined as an event that causes the skin and underlying tissue to die due to hypoperfusion concurrent with severe dysfunction of another organ system [2]. The National Pressure Ulcer Advisory Panel defined unavoidable PU as an ulcer that forms because of an individual's clinical conditions and risk factors, despite the proper application of standard preventative measures [5]. A Kennedy terminal ulcer is defined as unavoidable skin breakdown or skin failure associated with the dying process [4]. Because of the absence of clear diagnostic criteria, these terms are often used inappropriately.

In patients at risk of ASF, patients and caregivers need to be informed that ASF is unavoidable despite standard preventative measures. Delmore et al. [1] found that peripheral arterial disease, mechanical ventilation for more than 72 hours, respiratory failure, liver failure, and severe sepsis/septic shock predicted the development of ASF. Curry et al. [6] reported that renal failure, respiratory failure, failure of more than one organ system (not including skin failure), and an albumin level $<3.5 \mathrm{~g} / \mathrm{dL}$ were related to ASF development. In our case, the patient's albumin level was lower than $<3.0 \mathrm{~g} / \mathrm{dL}$, and he had respiratory failure and renal failure with septic shock. The use of vasopressors has
Table 1. Differences between pressure ulcers and acute skin failure [1]

\begin{tabular}{|c|c|c|}
\hline & Pressure ulcers & Acute skin failure \\
\hline Color & Persistent redness & $\begin{array}{l}\text { Yellow/purple/black } \\
\text { discoloration }\end{array}$ \\
\hline Shape & Round & $\begin{array}{l}\text { Butterfly-shaped or pear } \\
\text { shaped }\end{array}$ \\
\hline Pathophysiology & $\begin{array}{l}\text { Ischemia secondary to } \\
\text { unrelieved pressure over } \\
\text { a bony prominence }\end{array}$ & $\begin{array}{l}\text { Ischemia secondary to poor } \\
\text { perfusion related to acute } \\
\text { illness }\end{array}$ \\
\hline Mortality & Low & High \\
\hline
\end{tabular}

also been proposed as an influencing factor $[7,8]$. These factors strongly suggest that the patient in this case had ASF, not PU.

No standard criteria are available for the differential diagnosis of ASF and PU. Thus, it is plausible in the critical care population that many ulcers classified as PU are actually manifestations of ASF. There are some clinical differences between PU and ASF. According to Delmore et al. [1], PU presents as round, reddish lesions at bony prominences, whereas the lesions of ASF are described as pear-, butterfly-, or horseshoe-shaped, or sometimes as irregularly-shaped red/yellow/black ulcers, similar in appearance to abrasions that may occur suddenly (Table 1) $[1,9]$. The patient in our case had a pear-shaped ulcer on his left buttock with black lesions on the occiput, elbow, back, and ankle, which occurred at multiple sites simultaneously. The critical difference between PU and ASF is that there are many ways to prevent the former, whereas ASF may occur despite proper preventative measures.

ASF is a pressure-related injury that is found in patients with hemodynamic instability resulting from organ system failure. $\mathrm{PU}$ is preventable, whereas ASF is not; thus, misdiagnosis can lead to legal disputes. We concluded that the described case was ASF, not PU, for the following reasons. First, the multiple skin ulcers were caused by ischemia secondary to poor perfusion related to septic shock with multiorgan failure. Second, multiple skin ulcers occurred despite the implementation of proper preventative measures. Third, the shapes and locations of the ulcers did not correspond with those of typical PU. Fourth, multiple skin ulcers occurred simultaneously and rapidly.

For these reasons, we determined that the patient's diagnosis was ASF, not PU; therefore, although the appropriate precautions were taken, the skin ulcerations progressed. This was because of the patient's aggravated general condition, and was not the medical staff's fault.

To avoid legal disputes, it is important that a proper diagnosis be made quickly, and that physicians explain to patients and caregivers that ASF can occur despite the adoption of proper preventative measures. 


\section{NOTES}

\section{Conflict of interest}

No potential conflict of interest relevant to this article was reported.

\section{Ethical approval}

The study was approved by the Institutional Review Board of Dongguk University Gyeongju Hopital (IRB No. 110757201811-HR02-02) and performed in accordance with the principles of the Declaration of Helsinki. Written informed consent was obtained.

\section{Patient consent}

The patient provided written informed consent for the publication and the use of his images.

\section{ORCID}

Jung Hwan Kim https://orcid.org/0000-0002-9170-5764

Hea Kyeong Shin https://orcid.org/0000-0002-6248-7104

\section{REFERENCES}

1. Delmore B, Cox J, Rolnitzky L, et al. Differentiating a pressure ulcer from acute skin failure in the adult critical care pa- tient. Adv Skin Wound Care 2015;28:514-24.

2. Oh KS, Lim SY, Mun GH, et al. The treatment of pressure sore. J Korean Wound Care Soc 2005;1:83-6.

3. Langemo DK, Brown G. Skin fails too: acute, chronic, and end-stage skin failure. Adv Skin Wound Care 2006;19:20611.

4. Schank JE. Kennedy terminal ulcer: the "ah-ha!" moment and diagnosis. Ostomy Wound Manage 2009;55:40-4.

5. Edsberg LE, Langemo D, Baharestani MM, et al. Unavoidable pressure injury: state of the science and consensus outcomes. J Wound Ostomy Continence Nurs 2014;41:31334.

6. Curry K, Kutash M, Chambers T, et al. A prospective, descriptive study of characteristics associated with skin failure in critically ill adults. Ostomy Wound Manage 2012;58:3643.

7. Korupolu R, Gifford JM, Needham DM. Early mobilization of critically ill patients: reducing neuromuscular complications after intensive care. Contemp Crit Care 2009;6:1-11.

8. Cox J. Predictors of pressure ulcers in adult critical care patients. Am J Crit Care 2011;20:364-75.

9. Tran JP, McLaughlin JM, Li RT, et al. Prevention of pressure ulcers in the acute care setting: new innovations and technologies. Plast Reconstr Surg 2016;138(3 Suppl):232S240 S. 